\title{
Programa Participar: Software Educacional de Apoio à Alfabetização de Jovens e Adultos com Deficiência Intelectual
}

\author{
Wilson Henrique Veneziano ${ }^{1}$, Maraísa Helena Borges Estevão Pereira ${ }^{2}$, Tiago \\ Galvão Mascarenhas Freire ${ }^{1}$, Renato Domingues Silva ${ }^{1}$ \\ ${ }^{1}$ Universidade de Brasília (UnB) - Departamento de Ciência da Computação \\ Caixa postal 4466 - 70910-900 - Brasília-DF - Brasil \\ ${ }^{2}$ Secretaria de Estado de Educação do Distrito Federal \\ wilsonhe@unb.br
}

\begin{abstract}
Resumo. Este trabalho descreve as atividades de construção de um software educacional gratuito de apoio à alfabetização de jovens e adultos com deficiência intelectual. O software conta com recursos multimídia de áudio e vídeo para facilitar a interação do professor com o estudante. Estão contemplados os métodos de alfabetização mais populares atualmente, sendo que este software pode ser integrado a ferramentas educacionais usuais. O processo de validação com estudantes com Síndrome de Down, bem como deficiência intelectual com outras comorbidades associadas, mostrou que este software é uma ferramenta de ensino útil e eficaz. O software tem sido utilizado em escolas públicas e outras instituições de todas as Unidades da Federação.
\end{abstract}

\begin{abstract}
This paper describes the design, development and validation activities of a Brazilian educational software to support literacy for youth and adults with intellectual disabilities. The software supports audio and video to facilitate interaction with teachers and students. It includes the most popular methods of literacy; also it can be integrated with traditional educational tools. The results of the validation process with students affected by some types of syndromes have shown that this software is a useful and effective teaching tool. Nowadays, this software is used in all the Brazilian states.
\end{abstract}

\section{Introdução}

A revolução dos meios tecnológicos, principalmente no campo da informática, gerou uma necessidade emergente de capacitação e especialização de professores, no campo da educação [Lima 2006]. Diante desse contexto, a formação de profissionais para a área de Educação Especial, na perspectiva da Educação Inclusiva, torna-se imperativa nesse movimento. E um aspecto importante são as ferramentas de software educacional.

Especificamente no campo da educação de estudantes com deficiência intelectual, não existia, até o ano de 2012, no mercado brasileiro, um software adequado como ferramenta para o processo de alfabetização especificamente de jovens e adultos com deficiência intelectual. Existem alguns softwares educativos com o intuito de auxiliar o processo de alfabetização, embora a maioria seja voltada ao 
público infantil [Belan, Nery e Araújo 2005]. Há alguns voltados ao público adulto [Carvalho, Campos, Chagas e Nascimento 2008]. Porém, faltam softwares brasileiros para os adultos com deficiência intelectual. Isto porque as empresas privadas pouco produzem softwares educativos voltados a deficientes intelectuais. Note-se que esse tipo de software não deve ser infantilizado e precisa ser adequado às necessidades específicas desse público.

Nesse contexto, para o projeto, cujo produto é relatado neste artigo, traçou-se o objetivo de construir um software educativo gratuito que sirva como ferramenta de apoio a professores, atuando no processo de alfabetização de jovens e adultos com deficiência intelectual. O objetivo é contribuir para o aumento da oferta de ferramentas computacionais nessa área educacional, uma vez que os poucos aplicativos que existem são focados no público infantil.

É oportuno frisar a importância da linguagem escrita como instrumento social de interação pela qual um indivíduo pode exercer a sua cidadania. Essa preocupação se aplica especialmente no caso dos jovens e adultos com deficiência intelectual que cada vez mais se deparam, não somente com a exigência da alfabetização, mas também do letramento como habilidades básicas e habilidades de gestão para a contratação pelo mercado de trabalho e possam, assim, ter uma vivência mais completa e uma maior participação na sociedade. A questão social reflete-se na proposta deste software, que é dar apoio a alfabetização com funcionalidade social, possibilitando que o estudante possa interagir com a língua escrita por meio do computador e seja capaz de identificar letras, fonemas e se comunicar com o mundo utilizando o teclado do computador.

\section{Metodologia}

Foram percorridas as seguintes etapas, até que fosse obtido o produto, ou seja o software: estudos acerca de alfabetização de adultos e de deficiência intelectual, busca e avaliação de softwares educacionais especializados nessa área, visitas e entrevistas em escolas para se conhecer o perfil do público-alvo (professores e estudantes), levantamento de requisitos junto a professores experientes nessa seara, produção do software, validação do software em caso real de uso em escolas públicas, ajustes e acompanhamento dos resultados obtidos ao longo de um ano de uso do software. Além disso, foram estudadas experiências desenvolvidas por outros pesquisadores em educação de estudantes com deficiência intelectual [Canal e Brum 2004].

\subsection{Métodos e Metodologias de Alfabetização}

O debate sobre a eficácia dos diferentes métodos de alfabetização se estendem até hoje. Vários estudos tentam obter resultados conclusivos sobre a aplicabilidade destes métodos. Mas, atualmente não existe um consenso sobre qual o método mais adequado, mesmo na alfabetização tradicional. Isso se agrava quando o assunto é alfabetização de pessoas com deficiência intelectual. Mais ainda, quando se tratam de jovens e adultos.

Porém, alguns métodos de alfabetização são mais conhecidos e utilizados no Brasil, como o método alfabético (também conhecido como método silábico), o método fônico e o método Paulo Freire. Entretanto, para o software desenvolvido, buscou-se apreender aspectos da chamada alfabetização social e letramento. 
Esses métodos costumam ser empregados em conjunto, ao menos em parte, e de forma adaptada no ensino de pessoas com deficiência intelectual devido à inexistência de um método específico para esta clientela. Um aspecto importante a ser considerado na empreitada de alfabetizar é a afetividade do estudante, por meio de palavras e exemplos nas lições de forma que sejam significativos a ele, do ponto de vista afetivo, e de aplicabilidade no seu contexto social. Um pouco de cada um dos métodos supracitados está contemplado no software desenvolvido.

\subsection{Desenvolvimento do Software}

Com relação ao processo de software, que é o conjunto de atividades de produção de um software, optou-se pelo modelo evolucionário de desenvolvimento, pois ele intercala as diferentes etapas do desenvolvimento de software repetindo-as diversas vezes em ciclos. Considerando o tamanho deste projeto, foi uma escolha adequada.

Os padrões de projeto são modelos de soluções para problemas, permitindo que as implementações que os utilizam sejam genéricas e sofram menos limitações do seu contexto original. Devido à preocupação de desenvolver o software de forma que fosse de fácil manutenção e que pudesse ser estendido futuramente, optou-se pelo uso do padrão de projeto template method [Gamma, Helm, Johnson e Vlissides 2010].

Com referência à escolha de uma ferramenta de desenvolvimento, foi necessário usar uma linguagem que favorecesse a utilização de recursos multimídia, que foram muito utilizados no projeto, bem como facilitasse a comunicação com a Internet para permitir o acréscimo de recursos deste tipo no futuro. Também se levou em conta os custos de licença, procurando soluções gratuitas.

Após diversas análises de viabilidade, optou-se pelo Adobe Flash, que é uma plataforma de desenvolvimento muito utilizada em aplicações web e em sites. Contudo, também pode ser utilizada para o desenvolvimento de software stand-alone. Ele conta com diversas ferramentas de desenvolvimento produzidas pela Adobe e também com a runtime multiplataforma Flash Player, amplamente difundida em computadores pessoais. Os programas para a plataforma Flash são desenvolvidos na linguagem de programação ActionScript, que é uma linguagem orientada a objetos derivada do mesmo padrão que a linguagem JavaScript, o ECMAScript. O Flex SDK, que contém um compilador para ActionScript, é disponibilizado sem custos em duas versões: uma open-source e a outra proprietária com pacotes adicionais. Ambos os SDKs podem ser utilizados em conjunto com ferramentas de desenvolvimento gratuitas como a IDE Eclipse ou a IDE FlashDevelop.

\section{O Software Desenvolvido}

Ao software desenvolvido neste projeto foi dado o nome de Programa Participar. Isto porque, mais do que alfabetizar, espera-se que o software ajude os estudantes a participarem da sociedade, por meio da comunicação escrita e redes sociais na Internet.

\subsection{Requisitos Educacionais}

Os requisitos educacionais, que permeiam o Participar, foram pontuados a partir de entrevistas realizadas com professores da rede pública de ensino que trabalham com alfabetização de estudantes com deficiência intelectual. Essa atividade ocorreu durante 
as fases de levantamento de requisitos e de validação. A seguir, são apresentados alguns deles:

- Como o processo de alfabetização dos estudantes inicia-se com o aprendizado de letras maiúsculas, utilizou-se caixa alta em todas as telas destinadas aos estudantes. As telas de uso do professor possuem palavras e descritores em caixa baixa;

-A fonte Arial foi utilizada amplamente no Participar, por se tratar de uma fonte simples e de poucos adornos e a que mais se aproxima dos exercícios pedagógicos que $\mathrm{o}$ professor utiliza em sala e nas atividades de psicomotricidade;

-Todas as palavras foram representadas por fotografias reais, uma vez que alguns dos estudantes com deficiência intelectual têm dificuldade em trabalhar com situações hipotéticas e podem apresentar dificuldades na transposição do desenho simbólico para a representatividade do real;

- As palavras trabalhadas nos exercícios e nas lições foram selecionadas, de forma a serem significativas aos estudantes. Todas elas aparecem nas atividades da vida diária ou estão presentes no seu cotidiano;

- Orientou-se que a interface fosse enxuta e objetiva a fim de não dispersar a atenção do estudante ou confundi-lo com muita informação;

-O Participar faz uso de vídeos (600 exemplares), sons, imagens, animação de botões e destaque de objetos por serem recursos que auxiliam no processo ensino-aprendizagem de estudantes com deficiência intelectual;

- No intuito de que o estudante se identifique com o software, foram criados vídeos que o conduzam e o auxiliem nas tarefas propostas. Este elemento torna-se preponderante quando o estudante toma decisões corretas ou incorretas no Participar, ouvindo elogios ou incentivos para novas tentativas diante de erros;

- O Participar utiliza vídeos com foco na pronúncia labial para trabalhar letras, sílabas e palavras. A boa gesticulação e pronúncia adequada das letras e palavras são primordiais para a compreensão do estudante com deficiência intelectual frente à associação com a escrita das palavras primando pela pronúncia coloquial da língua portuguesa, sem considerar regionalismos preponderantes em muitos professores alfabetizadores.

-O Participar prima pela simplicidade, não existindo nele distratores, como vídeos, fotografias ou animações desnecessárias.

\subsection{Visão Geral do Participar}

Todas as telas de atividades possuem botões na parte inferior para avançar, retroagir ou deslocar-se ao menu principal. Além disso, existem botões nos vídeos que permitem parar ou iniciá-los novamente, e antes de acessar a página de exercícios é possível configurar o que será visível para o estudante.

Estão presentes vídeos-guia para conduzir o estudante por todo o aplicativo, orientá-lo a respeito dos procedimentos que ele deve realizar, e informar se a resposta está ou não correta nas diferentes categorias de exercícios. O vídeo labial, por sua vez, pronuncia letras, sílabas e palavras (Figura 1). 


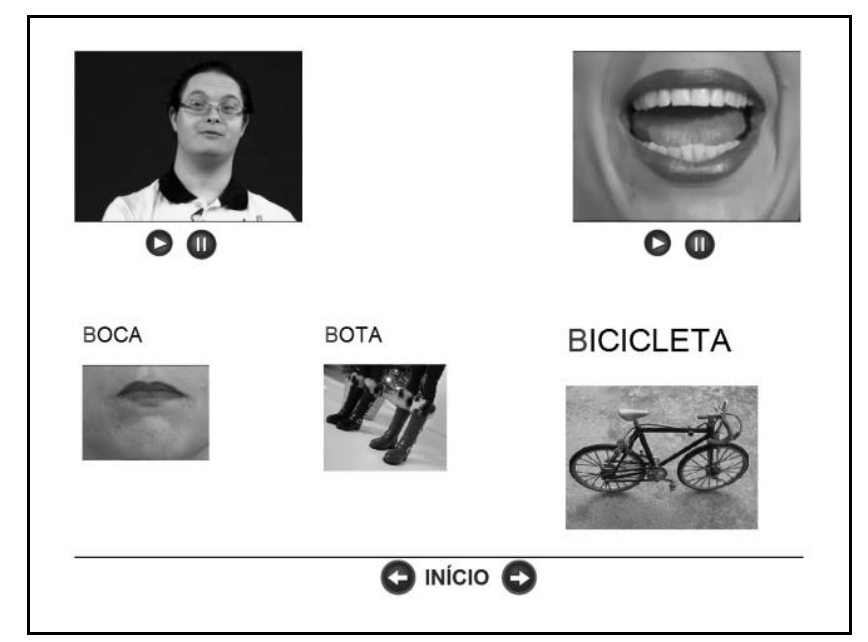

Figura 1: Vídeo-guia (canto superior esquerdo) e labial (canto superior direito).

\subsection{Módulos de Atividades}

O Participar possui três módulos de atividade: Explorar Teclado, Lições e Exercícios (Figura 2). Cada um deles exerce uma função específica dentro do contexto educacional do software. A seguir, cada um desses módulos encontra-se descrito.

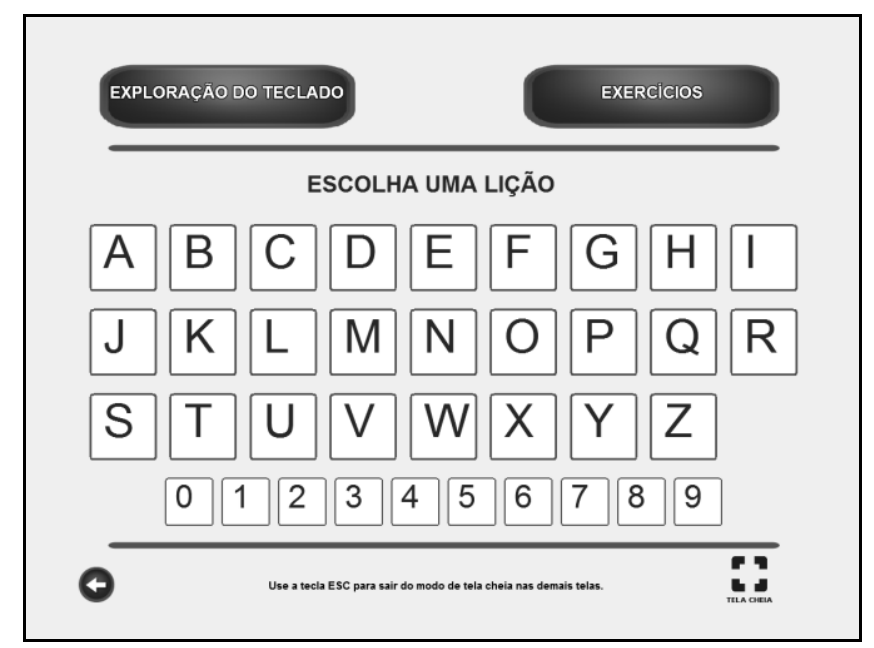

Figura 2: Menu Principal.

\section{Explorar Teclado}

O módulo Explorar Teclado tem como finalidade associar a tecla pressionada à pronúncia correta e bem articulada com o som correspondente da letra, apresentando simultaneamente seu desenho, em caixa alta, no centro da tela. Essa atividade pretende, ainda, trabalhar a coordenação motora do estudante e familiarizá-lo tanto ao teclado virtual quanto ao teclado físico do computador.

\section{Lições}

Neste módulo o professor seleciona uma letra do alfabeto para trabalhar com o estudante em forma de lições. Para cada letra existem lições com objetivos específicos. 
Primeira lição - Ensino da letra. Na primeira lição o guia propõe um estudo da letra corrente, apresentando-a em seguida. O desenho da letra aparece na tela e, então, o guia pede que o estudante localize a letra no teclado e a aperte. Caso a letra correta seja pressionada, surge o vídeo com foco labial, no canto direito superior da tela, pronunciando a letra. Caso contrário, o guia emite uma mensagem de advertência.

Segunda lição - Escrita da letra. A segunda lição tem como objetivo demonstrar ao estudante como se escreve a letra que está sendo trabalhada. O vídeo da escrita pode ser parado em pontos específicos, a fim de se observar detalhes do desenho da letra, além do professor poder trabalhar nas atividades cotidianas de psicomotricidade (Figura 3).

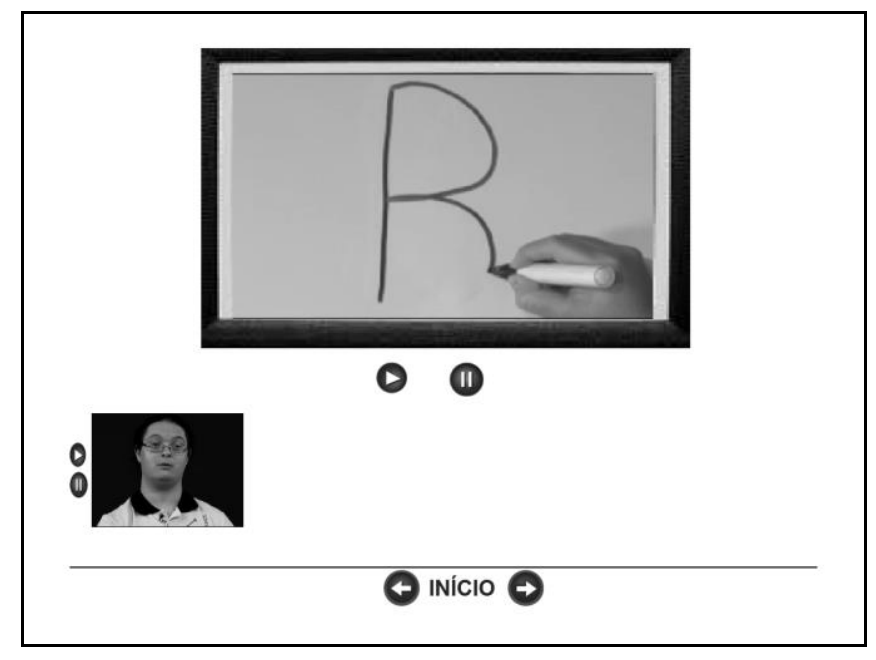

Figura 3. Ensino da grafia manual da letra B.

Terceira lição - Posicionamento da letra na palavra. Após conhecer a letra e ver como escrevê-la o estudante inicia a terceira lição. Nela ele é informado que a letra aprendida é usada em várias palavras. Simultaneamente são apresentadas três palavras com a letra da lição destacada e suas respectivas figuras. $\mathrm{O}$ guia solicita ao estudante que clique sobre uma das fotografias, para que ouça a pronúncia.

Quarta lição - Escrita da palavra. Na quarta e última lição o estudante completa a letra que falta na palavra. As palavras apresentadas aqui são as mesmas da lição anterior e a(s) letra(s) que falta(m) é a própria letra tema da lição, selecionada no menu principal. Nesta tela é possível ouvir e parar a pronúncia da palavra clicando nos botões de controle, ao lado do vídeo com foco labial. Caso o estudante acerte, o vídeo labial pronuncia a letra, o guia o elogia e a lição finaliza com a pronúncia da palavra. Caso contrário, o guia emite uma mensagem de advertência, encorajando o estudante a tentar novamente.

\section{Exercícios}

A principal atividade executada no módulo Exercícios é a escrita de palavras a partir do número de lacunas disponíveis na tela. Para assessorar o estudante durante o processo existe uma imagem, que representa a palavra, no canto superior esquerdo da tela. Logo abaixo, também à esquerda, o guia dá instruções a respeito das respostas dadas pelo estudante (Figura 4). 


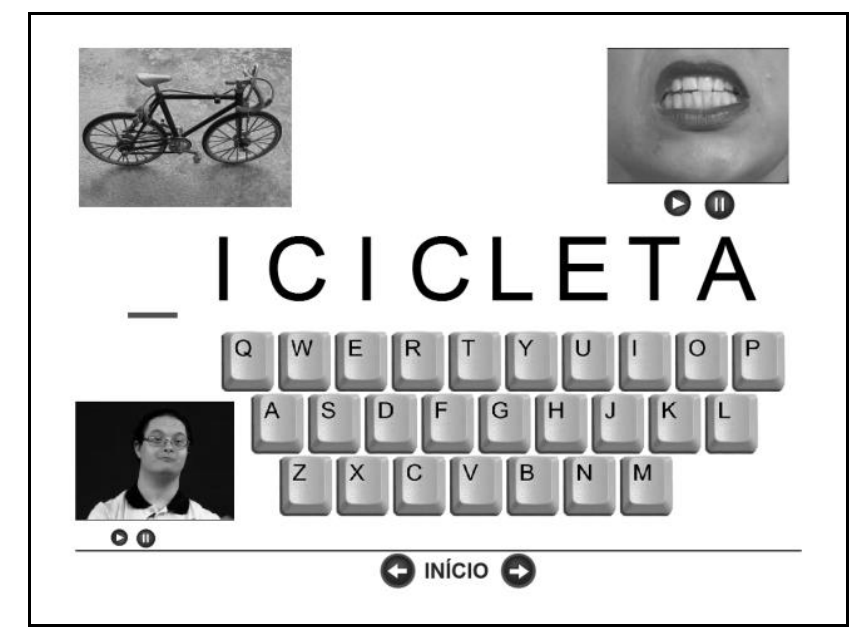

Figura 4. Exercício com a letra B.

Os exercícios estão separados por níveis de dificuldade e temas. Antes de entrar no módulo Exercícios é necessário que o professor configure a visibilidade dos níveis e o tipo de variação que o estudante verá. Os tipos de variações que podem ser aplicadas são:

-Trabalho sem auxílio: nesta modalidade de exercício não há dicas acerca da letra ou próxima sílaba da palavra;

-Trabalho por letra: nesta variação o som da próxima letra que falta é emitido para orientar o estudante;

-Trabalho por sílaba: nesta variação o estudante trabalha o uso de silabas, em vez das letras avulsas. O som da próxima sílaba é emitido para auxiliar o estudante.

Existe ainda a possibilidade de o professor explorar um simulador de bate-papo de internet com estudantes em estágio mais adiantado de letramento. $\mathrm{O}$ estudante interage com um personagem por meio de perguntas de assuntos cotidiano apresentadas em vídeos e também de forma escrita (Figura 5). Isso permite que o professor mostre ao estudante seus erros e acertos na linguagem, o que pode auxiliar no preparo dele para uso de redes sociais de internet.

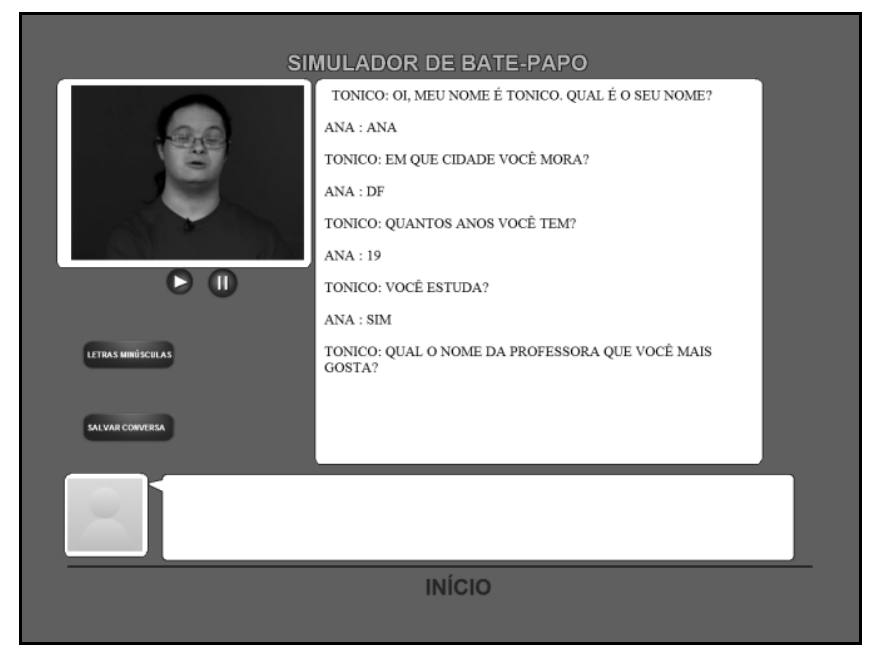

Figura 5. Simulador de bate-papo de internet. 


\section{O Processo de Validação}

No intuito de assegurar que o software Participar atendesse às necessidades de uma ferramenta pedagógica complementar mais condizente com a clientela atendida (jovens e adultos com deficiência intelectual), o aplicativo foi submetido a educadores e seus estudantes para validação em caso real de uso.

Durante o processo de validação foram realizadas visitas periódicas aos laboratórios de informática das escolas participantes. Estudantes e professores utilizaram um aplicativo-protótipo. Professores que trabalham diretamente com alfabetização de adultos com deficiência intelectual e múltipla, participaram desse processo, o qual ocorreu sob a monitoração dos participantes deste projeto.

A primeira fase ocorreu no ano de 2011. No período, houve ajustes no software, aprimorando-o. Basicamente três dinâmicas de abordagem foram adotadas: foco no professor, foco no estudante e uma terceira que relaciona a interação estudante/ professor/software.

- Na primeira forma de abordagem o software era apresentado unicamente ao professor. Nessa ocasião pontuavam-se os aspectos relevantes, sugerindo o acréscimo/retirada de funcionalidades ou elementos que escapavam ao propósito educacional.

-Nas ocasiões onde o foco da validação era diretamente o estudante, observaram-se itens como acessibilidade, facilidade de uso e motivação ao usar o software.

- Na abordagem que relaciona estudante, professor e software, a perspectiva de análise esteve voltada ao levantamento de sugestões de uso. Assim, foi possível identificar maneiras de associar o aplicativo às atividades pedagógicas já comumente utilizadas pelos professores.

Essas abordagens foram intercaladas ao longo do processo de validação, aplicando-se uma ou outra conforme necessário e em momentos oportunos.

Os estudantes que participaram da validação possuem deficiências diversas (Quadro 1).

Quadro 1: Deficiências dos estudantes que participaram da validação.

\begin{tabular}{c|l}
\hline CID & \multicolumn{1}{c}{ Deficiências } \\
\hline F72 & Deficiência Mental Severa \\
\hline F71 & Deficiência Mental Moderada \\
\hline F79 & Retardo mental não especificado \\
\hline & Síndrome de Down \\
\hline G80.9 & Distúrbio de conduta \\
\hline G40.9 & Epilepsia não especificada \\
\hline
\end{tabular}

Durante a validação ficou evidente que a receptividade dos estudantes, em relação ao Participar, foi positiva. Provavelmente, devido aos recursos multimídias embutidos na aplicação. Eles ficaram motivados com a novidade, acessando os módulos de atividades antes da orientação da professora. 
Um recurso implementado durante a validação, e agregado à tela de configuração, foram as variações de exercício. O fato do som da letra ou sílaba ser tocado, em forma de dica, contribuiu para que o exercício fosse adaptado a cada estudante segundo o seu nível de conhecimento e dificuldade.

Uma questão educacional importante contemplada pelo Participar, comentada constantemente durante a validação, diz respeito à pronúncia correta das letras $\mathrm{C}$ e $\mathrm{G}$. Dependendo da palavra, sua pronúncia ocorre de forma diferente, exemplo de gelo e goiaba. O mesmo pode-se dizer para a separação silábica, que apesar de ser trabalhada de forma diferente em algumas palavras, manteve-se o modo gramaticalmente correto de separação nas atividades.

Uma segunda etapa de testes ocorreu ao longo de outros doze meses, tendo sido finalizada em julho do ano de 2013. O software foi implantado em escolas públicas e organizações não governamentais de todas as Unidades da Federação. Foram colhidos relatos com sugestões de melhorias junto aos professores que utilizam a ferramenta. Com base nelas, o software passou por ajustes, chegando-se a uma versão mais aprimorada. A ferramenta está disponível gratuitamente para uso e será levada neste ano a países africanos de língua portuguesa (intermediação já autorizada pelo Ministério das Relações Exteriores do Brasil).

\section{Conclusões}

O software educacional descrito neste trabalho é uma ferramenta de apoio à alfabetização de jovens e adultos com deficiência intelectual, o qual deve ser utilizado com o professor regente e não é um novo método de alfabetização. Ele foi validado em escolas públicas, em caso real de uso. Estão presentes recursos multimídia que proporcionam a construção de tarefas interativas, que conquistam a atenção dos usuários. Por isso, nas lições e exercícios são trabalhadas palavras do cotidiano dos estudantes, a fim de que eles identifiquem-se com as situações em tela, inclusive do ponto de vista afetivo.

Foram colocados no software elementos comumente presentes nos métodos de alfabetização mais empregados no Brasil atualmente. Isso facilita ao professor associálo a outras ferramentas de ensino.

Um ano após o seu lançamento, ocorrido em 2012, o software está em utilização em todas as Unidades da Federação, em escolas públicas, organizações não governamentais e residências de estudantes. Professores dessas escolas têm relatado que seus estudantes beneficiam-se dessa ferramenta de ensino, tendo eles obtido crescimento educacional no campo da alfabetização, algo fundamental no caminho da inclusão social desse público.

O software está disponível no sítio www.projetoparticipar.unb.br.

\section{Referências}

Belan, P. A., Nery, E. P., e Araújo, S. A. (2005) Software para auxílio à préalfabetização infantil baseado em reconhecimento inteligente de caracteres manuscritos. XVI Simpósio Brasileiro de Informática na Educação - SBIE. 
Canal, A. P. e Brum, C. G. (2004) Interfaces para um Jogo Multimídia Direcionado a Portadores de Síndrome de Down. III Fórum de Informática Aplicada a Pessoas Portadoras de Necessidades Especiais . CBComp 2004.

Carvalho, M., Campos, M., Chagas, T., Nascimento, M. D. R. (2008) Desenvolvimento de Software Para Alfabetização de Adultos Baseado em Princípios Freirianos. Anais SBIE 2008.

Gamma, E., Helm, R., Johnson, R., e Vlissides, J. (2010) Design Patterns: Elements of Reusable Object-Oriented Software. Addison-Wesley.

Lima, P. A. (2006) Educação inclusiva e igualdade social. AVERCAMP, São Paulo. 